\title{
Os Desafios Enfrentados pela Licenciatura em Computação que a Comunidade de Educação em Computação Precisa Conhecer
}

\author{
Wilk Oliveira ${ }^{1}$, Rozelma França ${ }^{2}$, André Lemos ${ }^{3}$, Marcia Kniphoff da $\mathrm{Cruz}^{4}$, \\ Pasqueline Scaico $^{5}$, Haroldo Amaral ${ }^{6}$, Lilian Pereira Teixeira ${ }^{7}$
}

\footnotetext{
${ }^{1}$ Universidade de São Paulo (USP), ${ }^{2}$ Universidade Federal Rural de Pernambuco (UFRPE), ${ }^{3}$ Instituto Federal do Triângulo Mineiro (IFTM), ${ }^{4}$ Universidade de Santa Cruz do Sul (UNISC), ${ }^{5}$ Universidade Federal da Paraíba (UFPB), ${ }^{6}$ Universidade de Pernambuco (UPE), ${ }^{7}$ Instituto Federal de Educação, Ciência e Tecnologia Baiano (IF Baiano)

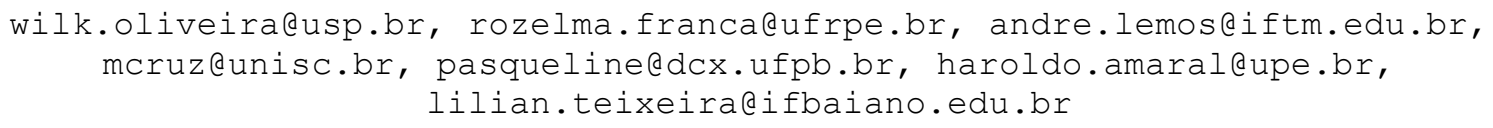

\begin{abstract}
In Brazil, for each component of schools' curricula, there is a specific training called "Licenciatura" required to teachers. This requirement is also the case for programs of teaching degree in Computer Science. However, several challenges are around them. In this paper, we present a position based on data from the Computer Science education community. Five of these challenges are highlighted, which we consider imminent. We hope to contribute to a proposition of actions that can strengthen these programs, training of Computer Science teachers, and, in general, the teaching of Computer Science in the Brazilian basic education.
\end{abstract}

Resumo. No Brasil, para cada componente do currículo escolar, há uma formação específica chamada "Licenciatura" exigida aos professores da educação básica. Esse também é caso dos cursos de formação de professores em Computação. Contudo, diversos desafios afetam esses cursos. Neste artigo, apresentamos uma posição com base em dados provenientes da comunidade de Licenciatura em Computação, destacando cinco destes desafios, que consideramos iminentes. Esperamos, com isso, contribuir para a proposição de ações que possam fortalecer estes cursos; a formação de professores de Computação, e, de um modo geral, o ensino de Computação na educação básica brasileira.

\section{Introdução}

Muito tem-se falado sobre a importância do ensino de Computação ainda na educação básica com o objetivo de aprimorar o raciocínio lógico e o pensamento crítico/reflexivo dos estudantes (Hartwig et al. 2019; Swanson et al. 2019), que são fatores importantes para a sua formação (Wing 2006; Brackmann et al. 2017). Da mesma forma, também tem-se argumentado com mais contundência a importância da formação em tecnologias na educação, isto é, o uso de tecnologias em sala de aula (Melo et al. 2019a; Machado et al. 2019).

No Brasil, todos esses aspectos são intrínsecos à formação do Licenciado em Computação, profissional formado pela Licenciatura em Computação (LC), curso apto a 
oferecer formação completa de graduação para o ensino de Computação na educação básica nacional (MEC 2016), como definido pela Resolução CNE/CES 5/2016, publicada no Diário Oficial da União (DOU), Brasília, em 17 de novembro de 2016 (Seção 1, págs. 22-24). O decreto destaca que os egressos do curso de LC, além de atenderem ao perfil geral previsto para os egressos dos cursos de Formação de Professores para a Educação Básica, estabelecidas por meio da Resolução CNE/CP no 2/2015, possuam dentre outros aspectos, sólida formação em Ciência da Computação, Matemática e Educação visando o ensino de Ciência da Computação nos níveis da Educação Básica e a formação de usuários da infraestrutura de software dos computadores nas organizações (MEC 2016).

A formação diferenciada que habilita especificamente para atuar no ensino de Computação na educação básica proporciona a atuação do egresso em toda e qualquer ação voltada à inserção e produção de objetos digitais e outros produtos tecnológicodigitais voltados à educação. Esta formação também se volta à capacitação das equipes escolares na condução do processo de inserção escolar no mundo altamente estruturado em torno dos recursos tecnológicos (Santos et al. 2017a; Santos et al. 2017b; Melo et al. 2019b) e das complexas ramificações da sua presença no mundo contemporâneo. Contudo, uma série de desafios se apresentam. Eles são gerados por diferentes problemas de caráter político, acadêmico e/ou sociais, influenciando diretamente no reconhecimento da atuação desses profissionais (Santos et al. 2017a; Santos et al. 2017b; Melo et al. 2019b).

Com o objetivo de registrar e promover a um patamar cooperativo e científico a discussão iniciada há mais de 23 anos (com o surgimento do primeiro curso de LC), apontamos uma série de desafios com a intenção de que possam ser enfrentados. Assim, este artigo apresenta um manifesto que busca resumir a opinião de parte da comunidade da LC no Brasil e incentivar a discussão na busca de maior reconhecimento e valorização dos cursos e seus egressos. O manifesto está sendo construído por professores com ampla experiência nos assuntos concernentes ao curso, baseado nas análises de produções científicas e outros documentos relacionados ao curso, bem como em discussões realizadas em diferentes eventos científicos (e.g., Workshop sobre Educação em Computação (WEI), Workshop de Informática na Escola (WIE) e Workshop da Licenciatura em Computação (WLIC). Como principal contribuição, apresentamos desafios e discutimos ações de enfrentamento para cada um deles.

\section{Manifesto}

Esta seção apresenta cinco desafios, organizados em subseções. Além da busca bibliográfica, foi realizado um evento de nível nacional reunindo professores e estudantes de cursos de LC das diferentes regiões do Brasil, a fim de discutir e traçar planos para o enfrentamento desses desafios.

\subsection{Por uma maior participação nas esferas sociais}

Um dos desafios atuais percebido é a falta de divulgação do curso para as diferentes esferas sociais. $\mathrm{O}$ enfrentamento a isto é propor e desenvolver ações que sejam capazes de divulgar amplamente os objetivos do curso enquanto formador de professores de Computação para atuação na Educação Básica. A partir desse desafio, propomos à comunidade seguir o que foi feito em outras comunidades (e.g., Pensamento Computacional), que foi criar um portal nacional que integre informações importantes 
sobre o curso (e.g., objetivos, instituições que os ofertam, publicações relacionadas e ofertas de emprego), bem como a elaboração de um documento contendo informações essenciais sobre o curso (e.g., perfil profissiográfico dos egressos e a relevância dos conteúdos da Computação para a Educação Básica) a fim de ser encaminhado aos conselhos estaduais e municipais de educação.

\subsection{Pelo reconhecimento dos direitos de atuação do Licenciado em Computação}

Após a regulamentação do decreto Resolução CNE/CES 5/2016 (MEC 2016), ficou definido que o Licenciado em Computação no Brasil, é o profissional apto para ensinar Computação na educação básica. Tal regulamentação necessita ser reconhecida como conhecimento integrante do currículo oficial e obrigatório da Educação Básica. Além disso, algumas regiões do Brasil promoveram concursos públicos abrindo vagas para professor de Computação na Educação Básica, contudo, sem a oferta de vagas para Licenciados em Computação. No intuito de enfrentar esse desafio propomos que haja uma representação das LC junto ao Grupo de Interesse de Educação em Computação (GIEC) e à Sociedade Brasileira de Computação (SBC), a fim de buscar atuar diretamente junto às instituições devidas para correta oferta de vagas nos respectivos concursos e fomentar o preenchimento das mesmas, garantindo os devidos direitos ao Licenciado em Computação.

\subsection{Por uma participação forte e conjunta/colaborativa nas esferas acadêmicas}

É necessário defender com maior apoio da comunidade científica das áreas de Computação e Educação, o fortalecimento de trabalhos que apresentem resultados inovadores na inserção de Tecnologias Digitais de Informação e Comunicação (TDIC) na educação, principalmente na Educação Básica, com o intuito de promover impacto acadêmico e social. A LC, em especial têm grande potencial com relação à produção de materiais didáticos e científicos especializados para o ensino de Computação na Educação Básica, bem como com os demais estudos que centram-se na área de TDIC e Educação. Tais produções podem demonstrar para a comunidade externa e para a própria comunidade acadêmica da Ciência da Computação, a importância e relevância do curso e de suas produções. No intuito de enfrentar esse desafio, é importante que a comunidade trabalhe de maneira colaborativa na produção acadêmica (i.e., produção científica) e na produção de materiais didáticos de qualidade e relevância nacional e internacional.

\subsection{Por um perfil de professor que atua em cursos de LC que atenda aos objetivos do curso}

Em alguns cursos de LC, como é o caso daqueles em que a maioria dos autores deste artigo leciona, os docentes que atuam na formação dos futuros educadores em Computação, são bacharéis em Ciência da Computação (e/ou cursos afins). Este fenômeno pode causar distorções na compreensão dos objetivos de um curso de LC e da importância da formação deste professor para atuar na Educação Básica. Essa situação tem levado professores a incentivarem o fechamento de cursos de LC em algumas regiões do país e a abertura de cursos de bacharelado similares aqueles em que se formaram. Para enfrentar esse desafio de forma mais escalável, propomos a criação de grupos de trabalhos interinstitucionais que articulem ações relativas à $\mathrm{LC}$, como é o caso de discutir os Planos Pedagógicos de Curso, como já ocorreu por exemplo, entre o 
corpo docente da Universidade Federal Rural de Pernambuco e o da Universidade Federal da Paraíba; envolvam os docentes em ações de conscientização quanto aos interesses e possibilidades do curso, de maneira que haja um maior incentivo para que os docentes se tornem agregadores às causas e missões da LC.

\subsection{Por uma maior diversidade de gênero na Licenciatura em Computação}

À medida que a profissão de professor se tornou cada vez mais feminina, os cursos de formação de professor acabaram por atrair um público que tem esse perfil. Conflita com essa tendência o processo de "masculinização" das carreiras ligadas à Computação (Nunes 2011; Nunes 2015). Dados de relatórios oficiais (e.g., Nunes 2011; Nunes 2015) e pesquisas recentes (e.g., Oliveira 2014; Santos 2017) têm mostrado um desequilíbrio desfavorável à presença de mulheres nos cursos ligados à Computação. De acordo com estes relatórios e pesquisas, apesar de ser um curso de formação de professores, o mesmo ocorre nas LC. Na ausência de estudos a respeito, somos levados a supor que o significante "Computação" se sobrepõe a "Licenciatura", na visão dos candidatos potenciais. No intuito de ajudar a dissolver essa tensão entre demarcações identitárias, e partindo do entendimento de que uma maior participação feminina nos cursos de LC pode ser um vetor particularmente significativo para que a imagem associada a quem procura carreiras ligadas à Computação seja mais aberta e plural, propomos um incentivo a ações que favoreçam a diversidade de gênero nos cursos de LC.

\section{Considerações Finais}

O curso de LC é responsável pela formação de professores para o ensino de Computação, já tendo formado mais de 150 turmas no Brasil. No entanto, uma série de desafios relacionados ao curso têm sido discutidos em diversas frentes. No intuito de destacar esses desafios e propor soluções para enfrentá-los, neste artigo, apresentamos um manifesto que formaliza uma urgente discussão, baseada em dados provenientes da comunidade de LC no Brasil. Cinco desafios e caminhos de enfrentamento foram apresentados. Espera-se que, através desse manifesto os olhares da comunidade acadêmica, política e civil, possam voltar-se ao curso em busca de enfrentar os desafios descritos. Além disso, fazendo prevalecer o caráter democrático da comunidade, expandimos este manifesto através de um formulário online ${ }^{1}$ aberto à comunidade, no intuito de conhecermos ainda mais a fundo outros desafios e, assim, expandir as contribuições para o fortalecimento do curso e da atuação do egresso.

\section{Referências}

Brackmann, C. P., Román-González, M., Robles, G., Moreno-León, J., Casali, A., \& Barone, D. (2017). Development of computational thinking skills through unplugged activities in primary school. In Proceedings of the 12th Workshop on Primary and Secondary Computing Education (pp. 65-72).

Hartwig, A. K., Silveira, M., Fronza, L., Mattos, M., \& de Araújo Kohler, L. P. (2019). Metodologias ativas para o ensino da computação: uma revisão sistemática e um

\footnotetext{
${ }^{1}$ Link para acesso ao formulário: https://forms.gle/iWAiUFco8evmzAuG6
} 
estudo prático. In Anais do Workshop de Informática na Escola (Vol. 25, No. 1, p. 1139).

Machado, G., Wives, L., \& Grandi, R. (2019). As comunidades de prática como ferramenta para formação continuada de professores: percepções docentes sobre o uso da tecnologia para compartilhamento e aprimoramento das práticas pedagógicas. In Simpósio Brasileiro de Informática na Educação (Vol. 30, No. 1, p. 1995).

MEC (2016) <encurtador.com.br/eBOU2> Acesso em, 30 de março de 2020.

Melo, E., Xavier, C., Nunes, C., Carvalho, R., Viana, F., \& Maia, D. L. (2019). A Tecnologia Digital e o Ciclo Investigativo na Formação Docente sobre Conceitos Estatísticos. In Anais do Workshop de Informática na Escola (Vol. 25, No. 1, p. 1414).

Melo, I., Rocha, N., \& Scaico, P. (2019). Eles não querem ser professores. In Anais dos Workshops do Congresso Brasileiro de Informática na Educação (Vol. 8, No. 1, p. $51)$.

Nunes, D. J. (2011). Ciência da Computação na Educação Básica, Disponível em: <http://www.adufrgs.org.br/artigos/ciencia-da-Computação-na-educacao-basica> .

Acesso em 20 de maio de 2017.

Nunes, D. J. (2015). Educação Superior em Computação, Estatísticas 2015. Sociedade Brasileira de Computação-SBC. Disponível em: $<$ http://www.sbc.org.br/documentosda-sbc/summary/133-estatisticas/1074-educacaosuperior-em-Computaçãoestatisticas-2015>. Acesso em, 06 de maio de 2017.

Oliveira, A. C., Moro, M. M., \& Prates, R. O. (2014). Perfil feminino em computação: Análise inicial. In XXXIV Congresso da Sociedade Brasileira de Computação (No. 1, pp. 1465-1474).

Santos, W. O. (2017). Mulheres na Computação: Uma análise da participação feminina nos cursos de Licenciatura em Computação. In Anais dos Workshops do Congresso Brasileiro de Informática na Educação (Vol. 6, No. 1, p. 814).

Santos, W. O., Hinterholz, L., \& Silva, C. (2017a). Licenciatura em computação: Desafios e oportunidades na perspectiva do professor. In Anais do Workshop de Informática na Escola (Vol. 23, No. 1, p. 705).

Santos, W. O., Silva, C., \& Hinterholz, L. (2017b). Licenciatura em computação: Desafios e oportunidades na perspectiva do estudante. In Anais do Workshop de Informática na Escola (Vol. 23, No. 1, p. 885).

Swanson, H., Anton, G., Bain, C., Horn, M., \& Wilensky, U. (2019). Introducing and assessing computational thinking in the secondary science classroom. In Computational Thinking Education (pp. 99-117). Springer, Singapore.

Wing, J. M. (2006). Computational thinking. Communications of the ACM, 49(3), 3335 . 